\title{
The Legal and Socio-Political Context of Urban Sustainability: Experiences from Greece
}

\author{
Kleoniki Pouikli, Foteini Kalantzi, Dimitra Dichala, Efthymios Katsoras, Koutoupa -Rengakou Evangelia ${ }^{1}$
}

\begin{abstract}
The aim of this paper is to outline the main legal and socio-political aspects relating to urban sustainability in Greece. This research focuses on the state of play of urban sustainability, as well as on the challenges relating to its implementation, based on an interdisciplinary approach, addressing legal, socio-political, and technical issues. Within this framework, emphasis is placed on Greece, a country that suffered through a long and severe economic crisis, whereby socio-spatial effects harmed a wide range of social groups. In this context, the paper focuses on the normative, jurisprudential, and policy reforms that took place due to and during the economic crisis, with respect to urban planning and land use. Moreover, it sheds light on smart city technologies, which ought to serve people's needs,especially those in vulnerable social groups,and it emphasises sustainable development, which at risk of being overstretched during an economic crisis. Finally, the paper also analyses the interrelation between urban sustainability and resilience, in the context of the natural disasters that affected Greece. By focusing our research on a southern European country that suffered through a long and painful socio-economic crisis, while also being prone to natural disasters, this research aspires to create a forum for dialogue with other countries facing similar legal and social challenges, and, hence, to engage in a comparative analysis that will help academics and policy makers take a step forward in the examination and implementation of urban sustainability, resilience, and smartness.
\end{abstract}

Keywords: urban sustainability, sustainable development law, human rights cities, urban planning,resilient cities, natural disasters

DOI: $10.7176 / \mathrm{JLPG} / 95-09$

Publication date:March $31^{\text {st }} 2020$

\section{Introduction}

Modern cities are constantly changing due to a set of complex and interdependent problems, such as global warming, overpopulation, public health issues, migration, financial crisis, marginalisation, natural resource depletion, and loss of biodiversity. Given this increasing and multifaceted pressure, existing systems and the traditional structures are becoming more fragile to different shocks and stresses, especially if one takes into consideration that by $2030,60 \%$ of the world's population is expected to live in cities.

Growing city populations and intensified urbanisation have brought to the forefrontquestions regarding city vulnerability on the one hand, and socio-economic inequalities on the other. Presently, these facts make the discussion on urban sustainability and resilience increasingly pressing. Urban sustainability has been vigorously discussed over the last thirty years. In the 1992 Rio de Janeiro Conference on Environment and Development (UN 1993), reference was made to the criticalaspects of sustainability, from an economic, social, environmental, and governance perspective. There, it was argued that unsustainable production and consumption patterns, as well as poverty, should be eliminated. Also, it has become a commonplace for urban sustainability indicators to encompass the so-called triple-bottom line (environmental, economic, social) (Elkington, 1999). The international trends of growing city populationsagainst a backdrop of increasing environmental degradation, coupled with the snowball effect of ever-increasing consumption levels, make social sustainability a global top priority.

In order to offset the effects of multiple environmental, socio-political, and financial shocks, it is essential to build up a regulatory framework to cope efficiently with the interconnected and evolving risks and disasters facing the urban landscape. The pillars of such a framework are sustainability, focusing mainly on improvingquality of life, with respect to environmental, social, and economic considerations, both as regards the present and future generations (Collier \& al. 2013), and resilience, highlighting the responsiveness of the systems to both extreme disturbances and persistent stress (Folke 2016).

The main goal of this paper is to map the state of play of urban sustainability, as well as to unpack the sociopolitical and legal challenges relating to its implementation. It is based on an interdisciplinary approach, which takes into account legal, socio-political, and technical aspects of urban sustainability. This particular approach integrates facets from three different disciplines, hence allowing for a comprehensive and multi-layered inquiry of urban sustainability, through the specific caseof Greece. It aims at examining urban sustainability issues, while shifting the spotlight to the human factor weaved into the urban fabric (human rights cities, New Urban Agenda). In addition, brief reference will be made to the issue of the smart city toolbox for increasing sustainability, as well

\footnotetext{
${ }^{1}$ Professor Koutoupa - Regkakou Evangelia was responsible for the advisory supervision and guidance of the researchers Kleoniki Pouikli, Foteini Kalantzi, Dimitra Dichala and Efthymios Katsoras
} 
as to the specific circumstances caused by economic crisis, which bring into question the interpretation and application of sustainable development. In doing so, examples will be raised from the case of Greece, a country that suffered through a decade of severe economic crisis, the socio-spatial effects of which harmed a wide range of social groups. In this context, emphasis will be placed on the normative, jurisprudential, and policy reforms implemented in Greece in the wake of the economic crisis. Hence,the paper addresses the methods through which urban environments- especially those in economic crisis - candeal with emerging socio-legal problems linked to sustainability, as well as how complex it is for policy-makers or judges to strike a balance between the conflicting interests underpinning the sustainable development framework-concept.

In this vein, the structure of the paper is the following:

Firstly, we are providing a theoretical framework, whereby we offer definitions for sustainability and sustainable urban development, along with points on the respective normative structures. Secondly, we frame our discussion in the socio-political context of sustainability and urban sustainability policy mapping. Furthermore, we focus on the practices and legal implications of urban development, focusing especially on urban planning processes in Greece. In particular, we concentrate on national environmental and urban planning policies during the economic crisis era, which spans the period from 2009 to 2018, approximately. Thirdly, we analyse the importance of 'smartness' in urban environments through the case of Greece, and how smart city mechanisms can strengthen urban sustainability. Fourthly, we look into urban sustainability in relation to resilience, a pertinent concept when examining the natural disasters that affected Greece.

\section{Theoretical Underpinnings: Definitions and normative framework}

\subsection{Unpacking the concepts of 'sustainability' and 'sustainable development'}

For the purposes of this paper, the term 'sustainability'can be defined as the dynamic balance required to predominate the process of peoples' interaction with the carrying capacity of an environment on which they depend, so that said people develop without causing irreparable damages to that environment (Ben-Elli 2015). As mentioned, the environment consists of the all structures that encompass societies, such as the economy and the natural environment.

Over the years several definitions have been formulated to fully define the meaning of sustainable urban development (Andrikopoulou\& al. 2014; Moore \& al. 2017). The most commonly used definition of this particular term, is the definition contained in the Brundtland report (UN General Assembly 1987): "Sustainable development is the development which covers its needs without jeopardizing the ability of future generations to meet their needs." The main goal of creating sustainable cities, is to imbue the urban fabric with the ability to survive under normal conditions, as well as to create those conditions so that it may cope with events that disrupt the balance of its system. For example, such events are both the emergence of a phenomenon of severe environmental destruction, and the disruption of economic stability.

Two approaches for sustainable cities as derived from the literature survey are:

- Smart sustainable cities (Urban ICT), where smart practices make cities viable using information technology in combination with the infrastructure, architecture, and general structure of cities (Höjer\&Wangel 2014; Deakin\& Reid 2018).

- Sustainable cities through urban planning (Andrikopoulou\& al. 2014). To achieve this goal there is a division into two sub-sectors, sustainable urban planning and environmentally sustainable cities, which are inextricably linked, since the development of one cannot be fathomed without the development of the other.

Over the years the two approaches have started to interact with each other, with the main objective of creating urban structures aimed at developing their societies, both in terms of the economy and the general living standards of their citizens, e.g. the construction of settlements governed by basic principles of sustainable cities, while integrating smart practices (Ghaffarianhoseini A. \& al. 2017).

Regarding the normative emergence of "Sustainable Development", this term was first mentioned in an environmental context in the 'Limits to Growth' (1972) by the Club of Rome. This idea was later reiterated by the International Union for Conservation of Nature (IUCN), and in 1987 in the renowned report, 'Our Common Future'(Brundtland Report 1987),by the UN World Commission on Environment and Development. Sustainability entails the integration of the environment into all development strategies and within all countries, not just the underdeveloped countries (United Nations 1987). The concept of sustainable development was officially recognised at the UN Conference on Environment and Development in Rio in 1992, while the World Summit on Sustainable Development in September 2002 in Johannesburg reiterated the central role of this idea.

At the EU level, sustainable development was recognised as an objective of European policy with the entry into force of the Treaty of Lisbon in 2009. Namely, it is enshrined in Articles 3(3)-(5) TEU, relating to the achievement of a high level of environmental protection, 21(2)(d)-(f) TEU, relating to EU external policy, 11 TFEU, establishing the principle of integration, as well as the Article 37 of the EU Charter of Fundamental Rights. As regards its interpretation at an EU level, the Advocate General Leger in case C-371/98, First Corporate Shipping, "the concept of sustainable development does not mean that the interests of the environment must 
necessarily and systematically prevail over the interests defended in the context of other policies pursued by the Community. On the contrary, it emphasises the necessary balance between various interests which sometime clash, but which must be reconciled" (para. 54). One significant EU policy document offering some guidance on how to implement sustainable development in practice is the 'Renewed EU Sustainable Strategy', which formulates eight "policy-guiding principles", serving as the main toolbox for the EU's approach towards sustainable development.

\subsection{Setting the socio-political context of sustainability}

There is a growing interest in the social aspects of sustainable development. Despite the fact that social dimensions have come into the picture when talking about sustainability, a clear definition is not yet in place (Dempsey $\&$ al. 2011). Social sustainability is defined, for example, by McKenzie (2004) as"a life-enhancing condition within communities, and a process within communities that can achieve that condition". Furthermore, it has been argued that there is limited literature focusing on social sustainability, a concept with multidimensionality and one that seeks to answer the question,"what are the social goals of sustainable development", as Dempsey et al. remark (2011).

Sustainability is usually associated with an environmental focus (Becker \& al. 1999, 4). Nevertheless, it describes "a field of investigation that is based on a society-oriented definition of problems" and is itself a social question (Partridge 2005).

Bramley and Power (2009) identify two main dimensions of the definition of social sustainability: social equity (access to services, facilities, and opportunities) and sustainability of community. The latter contains subdimensions such as "attachment to the neighbourhood, social interaction and safety within the neighbourhood, perceived quality of the local environment, satisfaction with the home, stability, and participation in collective civic activities" (Dave, 2011).

'Social sustainability' gains even more importance when focusing on countries that have gone through a severe economic crisis. Over the last decade, southern European cities and urban regions have been dealing with socio-economic challenges such as unemployment and increased levels of poverty, as well as with issues created by changes in the geopolitical arena and increased migration waves. Furthermore, austerity measures have had an impact at a national and local level. Specifically in Greece,according to Balabanidis\& al. (2013), socio-spatial effects of the crisis have impacted a wide range of social groups, whereby crucial developments include decreasesin the income and purchasing power of households, along with an increase in fixed operating expenses, mortgage indebtedness, and the taxation of residential property through new legislation (Serraos\& al 2018, 123). These developments affected many households that could not afford housing and decent living conditions - they had a particular effect on vulnerable social groups, such as immigrants, women, elderly people, and the unemployed (ibid). Moreover, there are visible effects on public space, whereby its quality and free use are often compromised. For example, in Athens, there is an exacerbation of the darker consequences of the crisis, such as drug use and trade, sex trafficking, and an increase in the number of unemployed and homeless people (ibid, 127).

\subsection{Normative and policy mapping of Urban Sustainability}

Cities have a particularly important role in sustainability transitions, because they are a locus for innovation, they provide great opportunities for learning and creating networks, and they offer possibilities of achieving changesof the entire system at local scales (European Environment Agency 2019). Urban sustainability is apparent in a variety of fields, such as built environment, transport, energy, sanitation, and waste management, and includes the gradual transition to larger proportions of renewables in urban energy production and distribution, shifts towards multimodal transport, and ICT-enabled mobility services.

The link between the realisation of human rights and the transition towards sustainability at an urban level constitutes a multidimensional and challenging issue, especially under socio-economic pressures, extreme poverty, unsustainable patterns of production and consumption, and natural disasters. Cities are well-positioned both to deliver services which are intrinsically connected to human rights issues, and to realise sustainable development goals (Gomes da Silva, 2018). This interrelationship is reflected in the concept of human rights cities, which are considered the optimum framework both for achieving the Sustainable Development Goals (SDGs) set in the 2030 New Urban Agenda, and for the realisation of human rights in urban areas.

Namely, the New Urban Agenda acknowledges the essential role of cities as a transformative force for sustainable development, suggesting a holistic and cross-cutting approach to the challenges of urbanisation, with human rights at the centre of the efforts (Gomes da Silva 2018). For the first time, the "right to the city", a concept introduced by the French Marxist philosopher and sociologist Henri Lefebvre (Harvey 2008), is explicitly enshrined in a UN text, stressing the need to use human rights standards to achieve the SDGs. In any case, the essential role of the cities is recognised in the stand-alone urban SDG 11, which calls for "detailing strategic actions necessary for ensuring that cities and human settlements, as the location of many development efforts support the implementation of the SDGs".

In this context, the concept of human rights cities has emerged as the appropriate framework for promoting 
and realising a human rights-based approaches in designing sustainable urban policies (Kjaerum\& al 2018). According to the 'Gwangju Declaration on the Human Rights City'of 2011, a human rights city is "both a local community and a social-political process in a local context where human rights play a key role as fundamental values and guiding principles" (para. 3), while also observing the right of all citizens to fully participate in decisionmaking and policy-implementation processes (paras. 4-5). In addition to this, Oomenhas defined a human rights city "as an urban entity or local government that explicitly bases its policies, or some of them, on human rights as laid down in international treaties" (Oomen 2016).

Given that a human rights city is inclusive, equality-driven, participatory, accountable, and nondiscriminatory, these key elements depend on three main pillars: societal development, a culture of human rights,and urban justice (Soohoo 2016). It is therefore clear that the achievement of SDGs through the lens of the localisation of human rights, corresponds to the pragmatic approach of shaping effective urban policies through better understanding of local needs and specific features. Hence, in this cross-cutting framework, human rights considerations and sustainable development requirements should be integrated into spatial planning and land use, local finance, legislation, and national urban policies.

Besides Goal 11, other Sustainable Development Goals related to key thematic issues are more relevant for cities, such as Goal 6 Clean Water and Sanitation, which aims at ensuring availability and sustainable management of water and sanitation for all, and Goal 7 Affordable and Clean Energy, which aims to "Ensure access to affordable, reliable, sustainable, and modern energy for all"; Two more goals are particularly important with reference to urban resilience: Goal 9 Industry, Innovation and Infrastructure, aiming to "build resilient infrastructure, promote inclusive and sustainable industrialisation, and foster innovation"; and Goal 13 Climate Action, aiming at "taking urgent action to combat climate change and its impact", with explicit reference to UNFCCC as the primary forum for global climate action (Tollin\&Hamhaber2017)

Concerning the policies against climate change, despite the fact that cities are seen as non-party stakeholders, their contribution to climate change adaptation and mitigation can be of paramount importance. Namely, as regards measures relating to the mitigation of the emissions causing climate change, mainly in the fields of transport and energy, as well as to plans and programmes addressing disaster prevention and management. The Paris Agreement directly mentions cities only twice within the text, outlining that stronger and more ambitious climate action requires the full support of non-party stakeholders, including cities [Section V, Paragraphs 134 to 137 of the Decision]. Recognising the important role of domestic policies and the need to strengthen and increase efforts, practices, technologies, and knowledge of local communities, including urban communities, cities are called upon to increase and upscale their efforts for both mitigation and adaptation actions, reducing emissions and building resilience, adapting to rapid and slow on-setting extreme climate events and enduring conditions; this requires more integrated and holistic approaches, aimed at developing and implementing systemic action, coupling mitigation and adaptation (Tollin\&Hamhaber 2017).

Beyond that field, the 'Global Pact for the Environment' (GPE) constitutes the latest development in this field.It reframes the debate relating to the effective realisation of the SDGs. Namely, the GPE was an initiative launched in 2017 aiming at unifying and reinforcing existing environmental law and principles, by formally recognising an individual right to a healthy environment at the international level (Parejo-Navajas 2018). On 10 May 2018, the UN General Assembly (the Assembly) adopted Resolution 72/277titled 'Towards a Global Pact for the Environment', which directly interrelated environmental protection with human rights obligations, such as the enjoyment of a safe, clean, and healthy environment.

Hence, the GPE adopts a rights-based approach to the environment, stressing the need for a transition to a system which will be able to tackle environmental challenges, as well as encouraging all public and private institutions to incorporate environmental rights considerations into plans, policies, and processes (Springer 2016). In this context, this initiative may form an answer to the universal call of the SDGs "to end poverty, protect the planet and ensure that all people enjoy peace and prosperity" (SDG 17), setting the framework for a more effective implementation and enforcement of the 2030 Sustainable Development Agenda. Given that neither the European Convention for the Protection of Human Rights and Fundamental Freedoms, nor the Charter of Fundamental Rights of the European Union explicitly recognise a human right to a healthy and safe environment, the GPE initiative may trigger new developments in the EU landscape.

\section{Seeking sustainable urban development: Practices and legal implications}

\subsection{Urban planning processes in the context of the Greek financial crisis}

In terms of the viability of cities in the event of an economic crisis, urban regeneration, as a tool for dealing with such crises, has been linked to every development that takes place in cities (Tallon 2010), as it aims at the simultaneous adaptation of the natural fabric, the social structures, the economic base, and the environmental status of the urban area (Kafkalas et al 2015), while urban design aims at more cohesive forms of urban development by avoiding urban propagation and diffusion (Czischke\&al.2015).

Urban regeneration can be defined as "a comprehensive and integrated vision and action which leads to the 
resolution of urban problems and seeks to bring about a lasting improvement in the economic, physical, social and environmental condition of an area that has been subject to change" (Roberts 2000). Basic tools for urban regeneration- from an urban planning perspective -are, firstly, the deployment of existing abandoned buildings and urban spaces, and, secondly, the preparation and implementation of the Integrated Urban Intervention Plan (SOAP) (Ekonomou 2004).

It is therefore understood that the complexity of the urban context, takes into consideration and includes a variety of spatial levels, sectors, actors, and disciplines (Stouten 2010), an essential condition to be met in order to address the crisis, which - despite its initial financial nature - affects diverse facets of urban life, such as economic, institutional and social aspects.

In Greece's case the basic principles of urban regeneration were, and still are, a tool with which to address the economic crisis. The implementation of urban regeneration attempts to achieve this through two strategies; namely, the creation of public-private partnerships, in order to deploy the existing public properties, as well as through the preparation and implementation of the Integrated Urban Intervention Plan (SOAP)(Kafkalas\& al. 2015).

The establishment of partnerships between the public and private sectors (public-private partnerships) contributes significantly to the urban development during a crisis period,given that they link successfully private and public sector interests by defining their roles as well as the concrete risks/uncertainties of urban development(Karadimitriou et al. 2013). Since 2008, the practice of using public property to attract private investment in the urban environment has emerged as one of the dominant positions, aiming at a more efficient and effective use of public property, and at addressing the economic consequences of the recession (Clark et al. 2010).For this reason, when the first effects of the economic crisis appeared in Greece, the accelerationand simplification of major property developmentfor investment purposes was pursued by a plethoraof laws, within the context of a different urbanand entrepreneurial development model, whichdiverged from the traditional model of Greek"SME capitalism" (Giannakourou\&Kafkalas2014). The main changes during this period, promotedas part of the country's bailout agreements, known as the Memoranda, are summarisedontwo axes: (a) the establishment of an independent non-governmental privatisation fund,the Hellenic Republic Asset Development Fund(HRADF), forthe sale of the public property, and (b) the provisionof a framework for spatial planning that facilitatesthe opening up of major public property developmentto private investment (Vitopoulou\&Yiannakou 2018).

As mentioned, the principles of urban regeneration can also be applied through the development and implementation of an Integrated Urban Intervention Plan (SOAP), which is a flexible tool that, however, implies and presupposes the coordination of bodies and objectives of various actors. A typical case is the centre of Athens, which faces complex and diverse urban crisis problems - with respect to social, developmental, environmental, and urban planning - thathave grown during the crisis period. This is illustrated by the abrupt change of urban functions in the city centre, the gradual movement of residents to suburban areas, the increasing number of abandoned sites, the exacerbation of social inequalities, the degradation of the urban environment, and the emergence of new solidarity structures and self-organising (Kafkalas\& al. 2015) necessary to maintain the preparation and execution of an Integrated Urban Intervention Plan (SOAP).

More specifically, SOAP for Athens includes the ultimate goal of redefining the city centre of the capital, as the centre of an international and sustainable metropolis, through a systematic, continuous, long, and coordinated integrated intervention strategy (Kafkalas\& al. 2015). In this context, the key features of the intervention strategy focus on efficient management of public and private space and allocated resources, boosting competitiveness, spatial and social cohesion, adoption of innovative and modern forms of information management (SMART city), upgrading the image and identity of the area, spatial differentiation of strategy, development of special intense intervention areas with a catalytic role. In terms of the planning interventions that are included in the SOAP,they refer to the use of abandoned buildings, the revitalisation of open spaces, the creation of smart and green standards in central Athens, and,lastly, the increase of greenery in buildings (e.g. green roofs) (Kafkalas\& al. 2015).

In both strategies, several abandoned sites that occupy large areas in almost all urban structures in Greece, e.g. camps, are deployed in order to reduce the urban sprawl and, by extension, to counter the reduction of green areas and reintegrate these areas into the urban fabric. With these interventions intended to stimulate the local economy in recession, the development of a comprehensive strategy (vision) for the transformation and growth of the city,also aims at attracting the interest of investors. (Vitopoulou\&Karadimou-Gerolymbou2007). To accomplishall of this, the combination of the following uses should be applied: malls, shopping complexes, green areas, and hotels. A typical example is the use of the abandoned airport in the metropolitan area ofElliniko - Agios Kosmas, Prefecture of Attica, which has attracted several investment schemes. Furthermore, variations in design systems have been recorded in severalEuropean countries, including Greece, focusing on promoting growth and investing in real estate, thus creating a "standard" change with regard to space regulation. In Greece, it seems that in less than three years the financial crisis has succeeded in bringing about more significant changes to the residential urban and business development model, than all reform efforts of political changeover of the past overall (Andrikopoulou\& al. 2014).

The specific urban renewal policy analysis performed in Greece as well asthe urban interventions, showed 
significant correlations with urban regeneration policy, but there are critical shortcomings that must be diagnosed and treated in a more promotional and active urban policy. Regarding the use of public property through the establishment of the HRADF, concerns are occasionallyexpressedabout the proper use of public property, because of the lack of a coherent recovery strategy with clear development and urban planning objectives, as well as due to the inability of active participation of public administration instrategicallyplanned exploitation of public lands, as is made clear by the HRADF structure (Kafkalas\&al. 2015). On the other hand, it could be argued that with the involvement of private entities, infrastructure and development projects would not have been carried out under state supervision, such as, for example, regional airports on the Greek islands, the construction of which significantly contributed to the further growth of tourism. To summarise, the proper use of available public spaces and, even more so, abandoned public spaces in collaboration with the private sector through intervention strategies, can significantly contribute in dealing with economic and social crises.

\subsection{Urban sustainability and financial crises: striking a balance in Greek law}

Financial crises may affect national environmental policy in two ways: on the one hand, by transferring resources reserved for environmental purposes to financing other (more urgent) needs; on the other hand, by loosening or indirectly circumventing the existing cluster of environmental protective measures, in a bid to facilitate investments and speed up economic development(Gogos2017; Athanassiou2013). This shift regarding prioritisationsorely tests the balance between environmental protection and economic growth, which are both recognised and protected in the Greek Constitution. Greek law seems to mainly limit sustainability to its "green" aspect, which is treated as a dimension of urban competitiveness (Athanassiou2013). Under this one-dimensional and reduced notion of sustainability, which is aimed at cities with well-designed parks, city centres with pedestrian areas, adequate common spaces, a clean atmosphere, and sustainable mobility, it can indeed contribute to the attraction of investors, however it may also deter investments that oppose this reasoning.

It is thus interesting that environmental protection, as a variable of urban sustainability, has been treated, during the years of intensefinancial crisis in Greece, since 2010, both at a legislative and jurisprudence level in a contradictory manner: on the one hand, as an impediment to growth, and on the other hand, as a motive for the attraction of investments, aiming at "green development". The gradual effort of making the environmental and urban limitations and controls more lenient has been clear since 2009. While up to 2009 land use planning and the respective case law had the tendency of leaning towards forbidding constructing outside urban planning zones, during the time period that followed this was not expressly restricted (Gogos 2017). A short description of the main legislative regulations that have gradually allowed the legalisation of illegal structures and the gradually more lenient stance of caselaw regarding environmental protection demonstrates the constantly shifting weighting between environmental protection and financial interests, which, in times of intense financial crisis, favours the latter (i). Another interesting aspect are the dynamics that the exploitation of Greek state assets present, within the framework of the financial crisis and urban regeneration, in the light of the recent jurisprudence of the Assembly of the Council of State, which made possible the implementation of investments of huge financial importance (ii). Since 2010, a new generation of case law has emerged relating to environmental protection within the urban fabric, which, under the pressure of the ongoing financial crisis, overstretches the limits of the constitutional protective framework, and re-evaluates the application of the principle of sustainable development, strengthening economic growth.

\section{i."Legalisation" of illegal structures in the urban environment}

Initially, the potential of legalisation of illegal transformations of patios into main use spaces was provided by law in 2009 and 2010 (Laws Nos3775/2009 and 3843/2010), however the Assembly of the Council of State did not directly handle the issue of constitutionality of the respective provisions, as the possibility of mass legalisation of illegal structures was provided, upon the payment of a levy, pursuant to new legislation (Law No4014/2011), before the judicial decision (AssCoS 1971/2012) was published. An "environmental balance" was also established, since it was provided that the levies collected would be paid to the Green Fund, to be used for the restitution and improvement of the urban environment. The Court decided that collection purposes alone could not establish a reason for a state benefit that would justify the establishment of regulations with a broad impact on the environment, such as these controversial regulations (AssCoS 3341/2013 and 1118-19/2014).

The Court also noted that, in this way, even in times of intense financial crisis, fiscal public interest cannot justify blows to constitutionally established goods, such as the natural and urban environment. Also, it was decided that mass exemption from demolition of illegal structures built after 1983, is unconstitutional, claiming a violation of the constitutional order for spatial and urban planning with rational and scientific criteria, with the rationale that this controversial regulation would lead to the alteration of the functionality of housing complexes and to the deterioration of the living conditions of the residents, as legalisation is not connected - accordingto the provisions of law - withthe ad hoc assessment of the consequences of each individual illegal structure to the natural and habitual environment.Law No4178/2013 essentially repeated the provisions of Law No4014/2011 regarding mass exemption from the demolition of illegal structures upon payment of a levy. Judging the constitutionality of these 
provisions, the Assembly decided that the mass legalisation of illegal uses and structures is allowed by way of exception, as long as it is substantiated that this solution is imposed by major public interest and that, at the same time, measures are taken to prevent the repetition of arbitrariness, and to ensure that the impact to the environment and livingconditions would be the minimum possible (AssCoS 1858/2015). This decision marked a shift in the respective case law, which had until then, as a rule, consistently accepted the rigorous demolition of the new illegal structures (after 1983), and, for the first time, it was deemed acceptable that major public interest made relevant the protection of the urban environment. The Court took into consideration the real situation created by the existence of many illegal structures in Greece, the impossibility of their demolition without exemptions, and, without mentioning this explicitly, the cash benefit for the state stemming from their maintenance for a price. The strong minority of 10 Counsellors ensured the "collective memory of the Court" (Gogos 2017), by noting the existing case law in relation to illegal building. The recent natural disaster with the flooding in Mandra, Attica, and the fire in Mati, clearly underline the importance of rational urban and spatial planning and the strict stance of the Court against legislative efforts to legalise illegal structures.

\section{ii. The exploitation of the Greek state assets:}

a) The assets transferred to the Hellenic Republic Asset Development Fund (HRADF).

According to its founding Law No 3986/2011, the Hellenic Republic Asset Development Fund (HRADF) leverages State private property assigned to it by Hellenic Republic, according to the country's international obligations and the Medium-Term Fiscal Strategy. In close cooperation with the Greek Government, the HRADF promotes the implementation of privatisations in the country, with full responsibility for the application of the respective policy. The materialisation of the Fund's privatisation programme is under way, and its sole mission is the maximisation of development by attracting direct investments in infrastructures, energy, real estate, and other fields, while achieving additional important benefits, such as job creation, infrastructure modernisation, and the promotion of necessary reforms.

The case law regarding the Fund largely allows the realisation of its projects. For example, the Council of State avoided judicial control of the decisions regarding the privatisation of state-owned enterprises, rejecting as inadmissible annulment requests that were filed, ruling that the abovementioned decisions are not enforceable and, in some cases, that the applicants lacked any interest to act (locus standi) (Ass. CoS 1906, 1909, 2179, 2180, 2182, 2184, 2189/2014). Similar is the case law concerning the privatisation of ports (Ass.CoS 1129, 1144/2016) and airports (CoS 1985, 1986/2016) (Prevedourou 2016). The Court also decided that forests and woodlands belonging to the State, public entities, and public companies may be transferred to the HRADF (CoS 4883/2014), while underlining that this transfer does not affect the constitutional protection of forests.However, in reality, this position that forests and woodlands belong to the private property of the State, violates their nature as public shared goods and the "environmental acquis".

Regarding the assets transferred to HRDAF, it is characteristic that recently the Assembly of the Council of State allowed a major investment, the construction of works in the metropolitan area of Elliniko - Agios Kosmas of the Prefecture of Attica, of a total value of approximately 6 billion Euros; the investment includes the construction of 6 200-meter buildings (skyscrapers). The Assembly of the Court found, regarding the requests for annulment of the presidential decree, with which the Integrated Development Plan of the controversial 6 million square metre area was approved, that the buildings in question, of special architectural design, would be considered landmarks, and, interpreting the provisions of Law No 4062/2012, it decided that: on the one hand, the number of 6 special buildings is rational, in order for these to fulfil their architectural function as landmarks, and, on the other hand, that according to the architectural studies accompanying the plan, it is not definite that the maximum provided height of 200 meters will be exhaustive.

The Court rejected by majority the annulment request, according to which the provision for buildings of such height is opposed to the constitutional order for the protection of the natural environment of Article 24(1) of the Constitution, which also includes the landscape. Similarly, it decided by majority that, with the controversial actions, the provisions of Article 24 of the Constitution, by which the natural and cultural environment is considered to be a constitutionally protected value, are not violated, and that the applicants' claims that the planned works detract from the value of the environment and aggravate living conditions in nearby areas, were also rejected. The arguments formulated by the strong minority underlined the existing jurisprudence of the Council of State, which provided for greater protection for the natural, urban, and cultural environment (Sakellaropoulou 2018).

\section{b) The Olympic Games immovable property.}

After the end of the 2004 Athens Olympics, the sites built, projects of enormous economic value, were abandoned. At the beginning of the financial crisis, the Greek government made efforts to reuse the venues, by changing their use by law, so that it would be allowed to develop malls, restaurants etc., which would attract investors and accelerate the economic growth. The Assembly of the Council of State decided that such legislative changes of urban planning are not forbidden, but it was noted that "environmental acquis" (Koutoupa-Regkakou 2008, Siouti 2018 ) is to be respected; this means that new provisions must not be more adverse than the previous ones with regards to the existing natural and urban environment, and that, in any case, even if the new provisions do not 
respect the "environmental acquis", they may be tolerated if justified by a special urban planning cause(Ass CoS 376/2014) (Gogos 2014, Giannakourou2015). The jurisprudence regarding the Olympic venues does not contradict the former stance of the Council of State, but it allows the Court to weigh up the various interests involved and take into consideration the special characteristics of each case, before reaching the best legal solution.

\section{Strengthening sustainability through smart city mechanisms}

\subsection{The importance of "smartness" in urban environments: experiences from Greece}

Therelationship between urban environments and human beings is an evolving and ever-changing process. Currently, this relationship - especially when looking at mega cities - isdefined by high urbanisation, where the "right to the city" has been compromised. At the same time technology has been evolving at such a pace that it can offer solutions for the improvement of people's lives within these highly urbanised human habitats. Nowadays, information technology combined with infrastructural and architectural innovation could potentially transform cities into 'smart cities', the main goal of which is to integrate technology as the basic infrastructure in overcoming contemporary difficulties, such as overpopulation in large cities, and urban planning shortcomings.Smart cities' importance lies in the combination of three kinds of intelligence: connection of human skills, institutional mechanisms, and digital spaces operating in a community (Komninos, 2008), whereas some indicative smart city elements can be found in water and pollution management (i.e. "smart bins" signalling when to be emptied), modernised forms of transportation (i.e. connected traffic signals monitoring utility use), and wireless internet services.

It is undeniable that smart cities aspire to cope with their development challenges, sustainability, and security, while providing better living conditions and improved daily life for their citizens and visitors (Angelidou2014). However, they offer hundreds of solutions that allow communities to improve the economy, infrastructure and general interest services, and the environment (Komninos 2018), by saving energy and reducing pollutants, by applying smart Practices (Deakin\& Reid 2018). More specifically, they offer new methods of technology and information, they improve the governance and operational efficiency of administration in both the public and private sectors, and they bring about changes in the behaviour of citizens by offering solutions in the shortest possible time. In fact, sharing and the ability to reproduce solutions are indicators of maturity in a smart city, particularly by developing standardised repetitive processes, adopting service-oriented architecture, and using open platforms in various administrative divisions of cities (Komninos \& al. 2018).

It is noteworthy that integrating information and communication technologies (ICT) with natural infrastructures is a top priority in policy-making, both at a local and central level, with aiming at achieving smart and green living, improving energy efficiency, protecting the environment, improving quality of life, and enhancing the competitiveness of the economy (Mahapatra \& al. 2017).

The combination of the above in the smart city planning context,is divided into three innovation circuits, which include the creation of a new layer of digital space and technologies with the capacity to change and optimise all aspects of cities: the economy, life, utilities, and governance, better informed decision-making and governance of public and private investments, which drive change in cities, and more efficient citizen behaviour, based on urban awareness that guides the use of urban space and infrastructure through intelligent systems, such as GPS and sensor-based solutions (Komninos \& al. 2018). All this combined with sustainable urban development creates an integrated urban development scheme that aims to design the cities of the future. They will provide citizens with improved security, living conditions, and capacity development in all sectors, in order to ensure the present and the future generations.

In recent years, both the central government of Greece and local administrations have turned to the implementation of actions aimed at creating viable urban tissues. Regarding efforts at a local level, in order to achieve this objective, smart practices are usedin some cases, such as in the Municipality of Trikala (The Guardian 2018) and the Municipality of Karditsa (CIVITAS 2020 2018), while in other cases sustainable urban development practices are used, such as in the Municipality of Thessaloniki (Andrikopoulou\& al. 2014), with the implementation of strategic spatial planning. More specifically, the Municipality of Trikala designed and applied smart policies creating a plethora of applications in public service operations, which aim to provide long-term solutions for citizens' everyday life. Some of the most important applications implemented cover the integrated telematics network, in order to meet the needs of vulnerable groups, the mobiPARK controlled parking system, which focuses on tackling traffic problems in the city centre, as well as an integrated Intelligent Transport Information System (Tsarchopoulos 2013). Another innovative action of Municipality of Trikala is the electronic complaints system, which has had one of the greatest impacts on the lives of citizens (The Guardian 2018). Other cities are also moving in this direction, such as the city of Thessaloniki in collaboration with Aristotle University,with a research programme (Komninos \& Mora 2018) in which applications have been developed to improve citizens daily life, such as the telematics applications of OASTH and the intelligent Urban Mobility Management System of Thessaloniki (Tsarchopoulos 2013).

At a national level, over the last decade measures implemented are mainly intended to solve long-standing 
public administration problems, to improve the quality of citizen services, and to facilitate transactions with the public sector (see dianeosis.org, E-government in Greece). However, it should be noted that Greece is still ranked $26^{\text {th }}$ among EU Member States in the Digital Economy and Society Index (DESI) 2019 report, which monitors states' digital competitiveness based on five main criteria: connectivity, human capital, use of internet services, integration of digital technology, and digital public services (see DESI 2019 Greece report, www.ec.europa.eu).

\subsection{Socio-legal challenges relating to smart city mechanisms}

Given the constantly increasing implementation of smart city initiatives and measures by policy-makers and governments, and their constantly increasing and multifaceted impact on different aspect of modern life, smart city agendas ought to include priorities for environmental (ecological and "green" implications of urban growth and development), and social sustainability (social cohesion, sense of belonging). Inclusivity is a major element in order for smart cities to work. As Coe et al., (2000), argue, “...local community partnerships - not wires - are the fibres that bind smart communities" (Hollands 2008). Many cities around the globe aspire to become "smart", to achieve the positive outcomesthat IT has on urban issues. However, it has been argued that self-designated smart cities face difficulties in dealing with widening inequalities and social polarisation (Hollands 2008).

Hollands (2015) argues against the dominance of the corporate smart city model and he discusses how "urban entrepreneurialism" has left little room for ordinary people to participate in smart cities. He stresses that while life might be efficiently organised and environmentally sustainable, it is unclear what role citizens, governments, and corporations have played in its creation. In order to achieve the ideal sustainable smart city, policies need to focus on socio-economic equality and inclusivity. Also, an important aspect for the success of the smart city model, is that all stakeholders of the city,namely, citizens, public authorities, and economic stakeholders, need to come together in order for the smartness of the city to be facilitated (Geffray\&Auby 2017, 12). Additionally, one needs to consider smart city side effects, such as extreme dependency on technology, and corporations dominating technology and related services (Yigitcanlar\&Kamruzzaman 2018).

In addition to this, the flourishing of the 'Internet of Things (IoT)'and blockchain technology - which is defined as a digital database containing information (such as records of financial transactions) that can be simultaneously used and shared within a large decentralised, publicly accessible network, andthe technology used to create such a database (Merriam-Webster) - as a significant aspect of smart sustainable cities, calls for a reexamination of the balance between innovation, on the one hand, and data protection on the other. Smart growth presents great potential for progress, however, it may also be used as a tool by those with the power to construct the urban smartness according to their interests.

A proposed solution is an interlinkage between bottom-up initiatives and public policy, whereby all stakeholders of the city, i.e. citizens, public authorities, and economic stakeholders, need to come together in order for the smartness of the city to be facilitated (Geffray \& Auby, 2017). Also, in order to achieve this balance, it is important to focus on the people, whereby technology will serve citizens and not the other way around. As Townsend argues (2014), what is needed is "good governance that serves the people and that avoids blind infatuation with the glistening toys of smart cities and an open-source approach to smart cities that solicits the creative intelligence of the people who actually live there, instead of the wholesale standardisation of smart cities through the global sales teams of a few corporations...".

As regards the legal challenges, the main issues arising concern privacy protection. The protection of personal data is established as an autonomous right in Art. 8 of the Charter of Fundamental Rights of the European Union and Art. 16(1) of the TFUE. It is different to the right to private life, which is established by Art. 7 of the Charter. The data flowing through smart cities include a lot of personal data, and anticipating legal problems may actually aid the growth of the IoT and the smart city(Losavio\& al. 2018), while also maintaining a fair balance between technology and innovation on the one hand, and citizens' human rightson the other. Some solutions may of course be found in technology:for examplePrivacy by Design, an approachaiming to protect privacy by embedding it into the design specifications of technologies, business practices, and physical infrastructures ${ }^{1}$, includes restricting the amount of data applications collect to the minimum, encrypting data flows as a default, making personal data held and used by public authorities and private stakeholders, etc. anonymous (Geffray\&Auby 2017),all of which contributes to privacy protection.

The EU has recently implemented the GDPR Regulation (EU 2016/679), which aims to unify and enhance data protection for individuals within the EU, as well as to regulate the use and flow of personal data between public and private stakeholders. The Regulation outlines six data protection principles that stakeholders need to follow when collecting, processing and storing individuals' personal data: 1. Lawfulness, fairness, transparency, 2. purpose limitation, 3. data minimisation, 4. accuracy, 5. storage limitation, and 6. integrity and confidentiality (see www.ec.europa.eu). Consent is quite possibly the most important ground for processingdata in EU DP law, the most global standard of legitimacy, and will most likely engender user trust. However, as noted, getting legally 
meaningful consent in IoT environments is a tough problem, as IoT systems, such as smart ambient lighting in a living room or smart thermostats, are designed to be "unobtrusive and seamless as a user experience", which means that they may collect information about the users' daily practices, while remaining "invisible in use" and "unremarkable" to users(Edwards 2015).As many commentators underline, users don't have the resources, opportunity, or motivation to give meaningful consent in the current online environment, and this is why ethical and legal constraints on data collectors are being promoted as a new approach(see the interdisciplinary project on Meaningful Consent in the Digital Economy at http://www.meaningfulconsent.org/).

\section{Weaving the tissue between sustainability, resilience, natural disasters, and crises}

\subsection{The emergence and establishment of the concept of "resilience"}

The discussion on urban sustainability issues in the Greek landscape is directly linked to questions relating to the concept of "resilience", given that Greece was recently hit by serious natural disasters with devastating consequences, as well as the socio-political shock of migration.In order to offset the effects of such pressures and crises, it is essential to build up a regulatory framework to efficiently cope with the interconnected and evolving risks and disasters in the urban landscape. The pillars of such a framework are "sustainability", focusing mainly on improving quality of life with respect to environmental, social, and economic considerations, both in the present and for future generations (Collier \& al. 2013), and "resilience", highlighting the responsiveness of the systems to both extreme disturbances and persistent stress (Folke 2016).

Despite their similar objectives and working principles, there is a systemic heterogeneity between them. Therefore, some scholars argue that resilience constitutes an integral part of the larger concept of sustainability (Ahern 2013), others that sustainability is a contributing factor to resilience (Chapin \& al. 2009; Saxena \& al. 2016), while according to a third opinion, resilience consists of an improved concept in comparison to sustainability (Vale 2014). In addition, resilience and sustainability have been conceived as separate concepts with (sometimes) contrasting objectives (Fiksel 2006) and no hierarchical relation between them (Hunt 2009; Redman 2014). For the purposes of this paper, resilience and sustainability are perceived as closely related but distinct concepts that have a complementary relationship in order to ensure human well-being, social equity, and environmental protection, as well as to maintain system dynamics despite uncertainties, disturbances, and nonlinear phenomena.

In this context, resilience can be defined as "the ability of households, communities and nations to absorb and recover from shocks, whilst positively adapting and transforming their structures and means for living in the face of long-term stresses, change and uncertainty" (Mitchell 2013). Boosting resilience in current legal and policy frameworks involves: i. actively understanding potential risks and how they impact systems - how society functions in each context, ii. determining at which layer of society those risks are best managed, and iii. applying a set of resilience principles to strengthen the system's capacity to absorb shocks or adapt and transform so that it is less exposed to shocks (Humbly 2014). In short, resilience can be boosted by strengthening three areas: Its absorptive capacity, adaptive capacity, and transformative capacity (OECD 2014).

Considering that the transition to sustainable cities constitutes one of the main tools for tackling complex crises, pressures and shocks by creating the appropriate conditions to cope with events that disrupt the balance of the system, it is essential to systematically promote resilience in Greece, especially in the wake of the recent devastating natural disasters. Hence, translating resilience into practice, urban planningconstitutes an effective toolbox that could substantially improve communities' preparedness and ability to recover from natural hazards or social and economic stresses, as well as strengthen their ability to diagnose, predict, and adapt (DesRoches\& Taylor 2018). According to the Multidisciplinary Centre for Earthquake Engineering Research, the main properties which systems must have in order to be resilient are (Bruneau \& al. 2003): Robustness, redundancy, resourcefulness, and rapidity.

\subsection{Boosting resilience in the in the framework of natural disasters: Examples from Greece}

Regarding Greece in particular, with the aim of creating resilient cities, as mentioned above, there are characteristic examples of areas that either implement sustainable development policies to cope with their vulnerability to severe environmental destruction phenomena, or they are forced to implement viable policies in order to tackle the emergence of a powerful natural phenomenon.

More specifically, the reconstruction of Kalamata after the earthquakes of 1986 sets a typical and noteworthy example. This is one of the rare cases of disaster reconstruction in Greece that was formulated, and which pursued goals of urban redevelopment, not limited to the rehabilitation of earthquake-prone buildings and infrastructure projects (Dandoulaki 2008).After the earthquake, the city was developed in a better and more rational way, based on the New Urban Plan that was designed to meet the new needs of the city. This Plan provided and ensured the necessary social spaces for the city's infrastructure. Also created were road crossings, free spaces, two secondary malls on the outskirts of the city, and a vessel area to transport carsthat were damagedin the earthquakes. Also, the surviving buildings of particular architectural and social value were restored, and the building coefficient and 
permissible construction height reduced. (Diamantopoulos 1990). This resulted in the creation, within 15 years, of an exemplary bioclimatic complex, a new municipal regional theatre, large pedestrian axes in older road, and amusement parks, as well as a marina on the city's western coast, which functioned as a breakwater, as before its creation the raging waves caused disasters for blocks throughout the city (Komioti 2016). It seems, therefore, that the earthquake disaster of 1986 functioned as a springboard for the city of Kalamata to create a modern resilient city, acting an example for the rest of the cities of Greece and southern Europe in countries with similar characteristics to those of Greece, at the level of urban planning.

Diamantopoulos (2007) noted that seismic urban planning is firstly urban and secondlyseismicplanning. It demonstrates the importance of pre-planning stages for post-earthquake phases through elaborating regulatory plans, while Baratos (2007) noted that we cannot rely on ex post improvisations and fragmented measures;instead we needorganised and systematic rehabilitation based on knowledge and experience.

However, in the recent past there have been cases of viable practices following major natural disasters, such as the floods in Mandra, Attica in 2017, and the devastating fire in the area of Mati at Attica in July 2018. According to recent scientific research, ten targeted actions have been proposed as a guide to enhance the viability in the Mandra area:

- Integrated delimitation of streams.

- Implementation of geo-spatial and geo-urban planning.

- Risk assessment parameter analysis for each water basin.

- Institutionalisation of a flood-resistant period (by fire analogy).

- Mild actions in critical areas (e.g. hydro works to hold water in higher areas to prevent flooding of lower areas).

- Back to clearing streams.

- Use of early warning and immediate mobilisation systems.

- Population information and awareness activities.

- Rational restructuring of competent body responsibilities, with a view to their more efficient and direct operation.

- Long-term hierarchical planning of measures and projects with hydrographic network interventions (Lekkas\&Diakakis 2018).

The institutional interventions proposed in order to enable the implementation of the aforementioned measures, are the following:

1.Constitutional revision for non-legalisation of illegal buildings.

2. The institutionalisation of a new Civil Protection framework.

3. The establishment of a flood and fire-protection building regulation according to Greek Earthquake standards.

4. The institutionalisation of a national Scientific Committee for the Assessment and Management of Natural Disasters.

5. The institutionalisation of Flood and Fire Hazard Assessment Committees, pursuant to the standards of the Seismicity Assessment Committee.

The actions that took place after the destruction of Mandra are moving forward, however, naturally, they have not been completed due to lengthy bureaucratic procedures. Nevertheless, it is absolutely essential for these policies to be implemented as soon as possible, as the current situation still risks creating serious problems in the daily lives of citizens, or,an even worse possibility, places citizens' lives at riskshould a similar physical phenomenon as that 2017 occur again. The reaction of the actors in the Kalamata case, where areas that suffered through major natural disasters have been reconstructed via specific sustainable planning practices, should be a guide for areas that have faced similar phenomena, in order for them to avoid the devastating consequences that characterise such phenomena. This reinforces the need to accelerate procedures both in Mandra and in other areas that have suffered catastrophic natural phenomena.Regarding the case of the devastating and lethal destruction in Mati, the actions to be performed are still in their early stages, since the Aristotle University of Thessaloniki study to record the state of the region was completed only a few months ago (Sarigiannis 2019). The first actions to move towards sustainable development in the region concern the restoration of environmental disasters, the normalcy of residents' livelihoods, and the restructuring of the road network in the wider area (Central Council of Urban Affairs and Disputes 2019).

In conclusion, the comparison of the natural phenomena inKalamata, Mandra-Attiki, and Mati, highlights the importance of creating viableresilient urban centres. Three equally dangerous natural disasters had a different impact on the lives of citizens, as in the first case the daily life of the citizens was not affected, while in the other two cases not only were the lives of citizens impacted by the phenomena, there were also, unfortunately, hundreds of victims.

It is also worth noting the inclusion of Greece's two largest cities, Athens (Athens Resilience Strategy for 2030: Redefining the city, 2015) and Thessaloniki (Resilient Thessaloniki: A Strategy for 2030, 2017), in the World Organisation of 100 Resilient Cities, which aims to exchange practices aimed at creating resilient cities through sustainable development. The two programmes developed in 2015 and 2017 have several similarities, as they set targets for sustainable transport and the creation of green growth, with the aim of achieving more general 
development in all sectors, such as social structure and the economy.It is important to note that in the target programme both cities have included smart and sustainable practices. For the time being, smart policies have been enforced (Komninos\& Mora 2018) mainly in relation to the implementation of sustainable practices.

\section{Concluding remarks}

This paper aspires to shed light on the multidimensional and complicated concepts of urban and social sustainability, as well as the normative and policy framework relating to the interpretation and implementation of sustainable development, especially in the context of the financial crisis. The emergence and the continuous evolution of these concepts is directly linked to the current challenges of the urban fabric, including climate action, economic and social resilience, natural disaster management, governance and decentralisation, and humanitarian urban crises. Hence, the need to effectivelyaddress urban sprawling and the unplanned, unmanaged, and uncontrolled growth of cities, is contingent upon the implementation of policies, strategies, and actions that promote and enforce sustainable development goals, by focusing on the multifaceted consequences of a severe economic crisis.

In this context, the paper exemplified through the case of Greece the impactsof the problems that emerge from such a crisis, on the social, legal, and technical levelof urban sustainability. Emphasis was placed on the developing technologies surrounding smart cities, which should highlight people's needs, especially those with increased vulnerability, as well as on the dynamic and constantly evolving content of the sustainable development concept, which may be overstretched in the wake of the economic crisis' consequences. Urban regeneration constituted one of the main tools of addressing the crisis, which, however, suffers from the lack of a coherent strategic plan. Also, during the crisis, it was very challenging to strike a balance between conflicting interests in the context of the sustainable development concept while simultaneously strengthening urban sustainability. However, despite the difficult legal and social problems that the Council of State faced over the past decade, it is important that the jurisprudence ensures sustainable development, even when the legislator deviates from this constitutional purpose.

Additionally, when looking into the interrelation between urban sustainability and resilience, the examples that we provided from the Greek case, showed the differentiation between the repercussions, especially towards people intwo different cases, depending on the existence of a sustainability and resilience policy framework. Lastly,by focusing on a country in southern Europe that suffered through a long and painful socio-economic crisis, while also being prone to natural disasters, this research aims to create a forum for dialogue with other countries that face similar legal and social challenges, hence engaging in a comparative analysis that will help us move forward with issues regarding urban sustainability, resilience, and smartness. Dealing with the aforementioned issues in a joint and integrative way, fuels the debate about long-term strategies and short-term guidesin tackling them, as well triggering active cooperation from all stakeholders involved at national and regional level, such governmental structures, political parties, the private sector, media, NGOs, and think tanks

\section{Acknowledgments}

This research is co-financed by Greece and the European Union (European Social Fund- ESF) through the Operational Program «Human Resources Development, Education and Lifelong Learning 2014-2020» in the context of the project " 'Sustainability', 'Durability', Resilience': The role of law in the new forms of cities in the context of the globalised urban space" (MIS 5004503).

\section{References}

1. Ahern J. (2013), Urban landscape sustainability and resilience: the promise and challenges of integrating ecology with urban planning and design, Landscape Ecology 28(2), 1203-1212

2. Allam, Z., \& Newman, P. (2018). Redefining the Smart City: Culture, Metabolism and Governance. Smart Cities, 1(1), 4-25.

3. Andrikopoulou E, Yiannakou A, Kafkalas G, Pitsiava - Latinopoulou M (2014) 'City and Urban Planning Practices for Sustainable Urban Development', Thessaloniki Kritiki Publishing (Greek)

4. Angelidou M. (2014), 'Smart city policies: A spatial approach', Cities, 41, S3-S11.

5. Athanassiou E. (2013). "Sustainable cities within the economic crisisin Greece", Available at: www.citybranding.gr/2014/12/blog-post $16 . \mathrm{html}$

6. Athens Resilience Strategy for 2030: Redefining the city (2015).

7. Ben-Elli M. (2015), 'Sustainability: Definition and Five Core Principles', The sustainability Laboratory, 1-7.

8. Bruneau M. \& al. (2003). A framework to quantitively assess and enhance the seismic resilience of communities, Earthquake spectra 19, 733-752

9. Central Council for Urban Affairs and Disputes (2019), 'Pre-approval of a Special Spatial Plan for the areas which affected of the fire at the Municipality apartmentsNeaMakri and Rafina of the Municipalities of Marathon and Rafina-Pikermi', 22nd May 2019 (Greek) 
10. Clark G., Notay A. and Evans G. (2010) 'Leveraging public land to attract urban investment. A ULI Urban Investment Network Report'. London: Urban Land Institute (ULI)

11. Collier M. et al. (2013). Transitioning to resilience and sustainability in urban communities, Cities, 32(1), 2128

12. Czischke, D., Moloney C. \&Turcu C. (2015). Setting the scene: raising the game in environmentally sustainable urban regeneration. In Sustainable Regeneration in Urban Areas, URBACT IICapitalization.

13. Dandoulaki M. (2008), 'Spatial design and earthquake-proof protection in Greece', School of Architecture, National Technical University of Athens.

14. Dave S. (2011). Neighbourhood Density and Social Sustainability in Cities of Developing Countries. Sustainable Development, 19, 189-205

15. Dempsey N., Bramley, G., Power, S., \& Brown, C. (2011). The Social Dimension of Sustainable Development: Defining Urban Social Sustainability. Sustainable Development, 19, 289-300.

16. Diamantopoulos (1990) 'Urban development of the city: The case of Kalamata 1980 -90',City and Earthquake,Technical Chamber of Greece, Athens

17. Deakin M., Reid A. (2018), 'Smart cities: Under-gridding the sustainability of city-districts as energy efficient-low carbon zones', Journal of Cleaner Production, 39-48.

18. Desroches R. \& Taylor J. E. (2018). The promise of Smart and Resilient Cities, The Bridge - Linking Engineering and Society, 13-20

19. Edwards, L. (2015), "Privacy, security and data protection in smart cities: a critical EU law perspective", CREATe Working Paper Series, 11.

20. Losavio M., Chow K.P., Koltay A., JamesJ. (2018). "The Internet of Things and the Smart City: Legal challenges with digital forensics, privacy and security", Security and Privacy, Special Issue.

21. Ekonomou D. (2004). 'Urban regeneration and urban renewal' Scientific publication of Technical Chamber of Greece, May 2004. (Greek)

22. Elkington J. M. (1999). Cannibals with Forks: Triple Bottom Line of 21st Century Business. Minneapolis, MN: Capstone Publishing.

23. European Environment Agency (EEA) (2019), Sustainability transitions: policy and practice, EEA Report, No 09

24. Fiksel J. (2017). Sustainability and resilience: towards a systems approach, Sustainability: Science, Practice and Policy 2(2), 14-21

25. Folke C. (2016). Resilience (Republished), Ecology and Society 21(4), 44-76

26. GeffrayE., Auby, J.-B (2017).“The political and legal consequences of smart cities”, Field Actions Science Reports, Special Issue 16, 11-15.

27. Ghaffarianhoseini A. et al (2017), 'Intelligent or smart cities and buildings: a critical exposition and a way forward' Intelligent Buildings International, 1-8.

28. Giannakourou G.\&Kafkalas G. (2014) Rethinking regional planning in times of crisis: necessity, contentand conditions of the reform. In: Massourakis M.\&Gortsos Ch. (eds) Competitiveness for Growth: PolicyProposals. Athens: Hellenic Bank Association, pp.511-522 ( Greek).

29. Giannakourou, G. (2015). "A first, comprehensive, review of the changes brought in the Greek planning system", Environment and Law (Perivallon kai Dikaio),1, 1-8

30. Gogos, K. (2014). The Environmental State, in Theodora Antoniou (Ed.), General Principles of Public Law, NomikiVivliothiki, 243-262.

31. Gogos, K. (2017). Economic crisis and urban environment in the jurisprudence of Council of State, in Economic crisis and environment in the jurisprudence of Council of State, Papazisis publishing, Also available: www.nomosphysis.org.gr

32. Gomes da Silva K. (2018). The new Urban Agenda and human rights cities: Interconnections between the global and the local, Netherlands Quarterly of Human Rights, 36(4), 290-310

33. Harvey D. (2008). The right to the city, New Left Review. 33, 23-40

34. Höjer M, Wangel J. (2014), 'Smart Sustainable Cities: Definition and Challenges', ICT Innovations for Sustainability, 333-349.

35. Humby T.-L. (2014). Law and Resilience: Mapping the Literature, Seattle Journal of Environmental Law $4(1), 85-128$

36. Hunt J. (2009). Integrated policies for environmental resilience and sustainability, Engineering Sustainability, issue: ES3, 155-167

37. Kafkalas G., Vitopoulou A., Gemenetzi G., Yiannakou A.\&Tasopoulou A. (2015) 'Sustainable Cities: Adaptation and Resilience in Periods of Crisis (e-book). Athens: Association of Hellenic Academic Libraries (Greek).

38. Karadimitriou N., de Magalhaes C. \&Verhage R. (2013) 'Planning, Risk and Property Development. Urban Regeneration in England, France and the Netherlands. Abingdon: Routledge. 
39. Kjaerum M. et al. (2018). Human Rights cities and the SDGs, Lund: Raoul Wallenberg Institute of Human Rights.

40. Komioti K. (2016) 'Earthquake disasters and residential reconstruction. Comparative analysis of the cases Zakynthos- Kalamata', Department of Planning and Regional Development, School of Engineering University of Thessaly

41. Komninos N. (2018), 'Smart cities', The SAGE Encyclopaedia of the Internet, 783-789.

42. Komninos, N. (2008), Intelligent Cities and Globalization of Innovation Networks, London and New York: Routledge.

43. Komninos N. \& Mora L. (2018), 'Exploring the Big Picture of Smart City Research', The Italian Journal of Regional Science, 15-38.

44. Komninos N., Tsarchopoulos,P.Kakderi C. \&Panori A. (2018), 'Smart City Planning from an Evolutionary Perspective', 1-18.

45. Koutoupa-Regkakou, E. (2008).Environmental Law, Sakkoulas, 61.

46. Lekkas E. (2018), 'Business Planning to reduce the impacts of catastrophic events on the Municipalities of Attica. The case of Mandra as a guide for reporting and improving emergency response, Regional Association of Municipalities of Attica'. (Greek)

47. Mahapatra C., Moharana A.K. \&. Leung C. M. (2017), 'Energy Management in Smart Cities Based on Internet of Things: Peak Demand Reduction and Energy Savings', MDPI.

48. McFarlane, C. (2019, October 18). Are Smart Cities The Pathway To Blockchain And Cryptocurrency Adoption? Retrieved from forbes.com: https://www.forbes.com/sites/chrissamcfarlane/2019/10/18/aresmart-cities-the-pathway-to-blockchain-and-cryptocurrency-adoption/\#36e 790b84609

49. McKenzie, S. (2004). Social Sustainability: Towards some definitions. University of South Australia. Magill, South Australia: Hawke Research Institute.

50. Mitchell A. (2013). Risk and Resilience: From Good Idea to Good Practice, OECD Development Cooperation Working Papers, No. 13, OECD Publishing.

51. Moore J.\& al. (2017), 'Developing a comprehensive definition of sustainability', Implementation Science.

52. OECD (2014). Guidelines for resilience systems analysis, OECD Publishing

53. Oomen B. (2016). Introduction: The Promise and Challenges of Human Rights Cities, in B.

54. Oomen B, Davis M. \&Grigolo M., Global urban justice: The rise of human rights cities, Cambridge University Press, 1-22

55. Parejo Navajas T. \&Lobel N. (2018). Framing the Global Pact for the Environment: Why It's Needed, What It Does, and How It Does It, Fordham Environmental Law Review, 30(1), 32-61

56. Partridge, E. (2005). 'Social sustainability': a useful theoretical framework. Paper presented at the Australasian Political Science Association Annual Conference, 28-30 September 2005. Dunedin, New Zealand.

57. Prevedourou, E. (2016). Recent jurisprudence regarding privatizations of airports and ports. Available at: www.prevedourou.gr.

58. Redman C. L. (2014). Should sustainability and resilience be combined or remain distinct pursuits?, Ecology and Society 19(2), 37-50

59. Resilient Thessaloniki: A Strategy for 2030 (2017).

60. Roberts P. (2000), 'The evolution, definition and purpose of urban regeneration', Urban Regeneration: A Handbook, 9-36.

61. Sakellaropoulou, A. (2018). Environment and Development: Balancing and judicial review, Available at: www.nomosphysis.org.gr

62. Sarigiannis D. (2019), 'Research for the scientifically correct picture of the environmental burden on the Mati', Auth Thessaloniki, 23rd July 2019 (Greek).

63. Serraos K., Greve T., AsprogerakasE., Balampanidis D.,\& ChaniA. (2018). Athens, a capital in crisis . In Knieling, J.\& Othengrafen F., Cities in Crisis: Socio-spatial impacts of the economic crisis in Southern European cities (pp. 116-138). Abingdon, Oxfordshire : Routledge

64. Siouti, G. (2018). Environmental Law Handbook, Sakkoulas, 6-7

65. Soohoo C. (2016). Human Rights Cities: Challenges and Possibilities, in Oomen B., Davis M.\&Grigolo M., Global urban justice: The rise of human rights cities, Cambridge University Press, 257-275

66. TallonA. (Ed.). (2010). 'Urban Regeneration and Renewal'. London: Routledge

67. The Guardian (2018). 'Inside Greece's first smart city: 'Now you don't need to know a politician to get something done', $4^{\text {th }}$ September 2018.

68. Tsarchopoulos P. (2013). 'Smart cities: Technologies, Architectural and eGovernment', Thessaloniki, 2013. (Greek)

69. TollinN. \&Hamhaber J. (2017). Sustainable and Resilient Cities: SDGs, New Urban Agenda and the Paris Agreement. Energia, ambiente e innovazione, 15(1), 8-15. 
70. Townsend, A. (2014). Smart Cities . New York : W.W.Norton.

71. UN General Assembly (1987). 'Our common Future, Report of the World Commission on Environment and Development (Brundtlant Report)', 4 August 1987.[Online] Available: https://sustainabledevelopment.un.org/content/documents/5987our-common-future.pdf

72. United Nations (UN) (2006). New Urban Agenda. [Online] Available: http://habitat3.org/wpcontent/uploads/NUA-English.pdf

73. UN General Assembly (2015). 'Transforming our World: the 2030 Agenda for Sustainable Development', 25 September 2015.

74. Vale L. J. (2014). The politics of resilient cities: whose resilience and whose city?, Building, Research and Information, 42(2), 191-201

75. VitopoulouA. \&Karadimou - GerolymbouA. (2007). Recovery of de-industrialization sites: Urban planning approaches and implementation issues. Announcement at the 5th Panhellenic Scientific Meeting of the International Commission for the Conservation of Industrial Heritage TICCIH-Greek Section, The End of the Giants. Industrial heritage and citytransformations, Volos 22-25 November 2007.(Greek)

76. Vitopoulou A.\&Yiannakou A. (2018) 'Public land policy and urban planning in Greece: Diachronic continuities and abrupt reversals in a context of crisis', European Urban and Regional Studies, 1-17.

77. Interdisciplinary project on Meaningful Consent in the Digital Economy. Available at: www.meaningfulconsent.org/.

78. Digital Economy and Society Index (DESI) 2019 report and Digital Economy and Society (DESI) Greece report. Available at: www.ec.europa.eu.

79. Yigitcanlar, T., \& Kamruzzaman, T. (2018). Does smart city policy lead to sustainability of cities? Land Use Policy, 73, 49-58. 